\title{
Current State of Value Management Implementations in Malaysian Public Projects
}

\author{
Aini Jaapar ${ }^{1}$, Nur Amani Maznan ${ }^{1}$, Mardhiah Zawawi ${ }^{1,2}$ \\ ${ }^{1}$ Faculty of Architecture, Planning and Surveying, \\ Universiti Teknologi MARA, Malaysia \\ ${ }^{2}$ Faculty of Civil and Environmental Engineering, \\ Universiti Tun Hussein Onn, Johor Malaysia \\ ainijaapar@salam.uitm.edu.my
}

\begin{abstract}
In Malaysia, Jaapar (2006) stated that Value Management (VM) is still at the early stage of its evolution. Despite its infancy stage, the authorisation of VM Circular 3/2009 by Economic Planning Unit (EPU) has made all public projects exceeding RM50 million to implement the VM studies. There are three objectives to be achieved in this research. The objectives are to identify the VM participants' receptiveness towards the VM implementation in a workshop environment setting, to observe the VM manual application in the VM workshop and to discover the challenges faced by the VM participants and facilitators.
\end{abstract}

Keywords: Value Management; VM Workshop Environment; VM Participants' Behaviour; VM Future Growth.

eISSN 2514-751X @ 2018. The Authors. Published for AMER ABRA cE-Bs by e-International Publishing House, Ltd., UK. This is an open-access article under the CC BY-NC-ND license (http://creativecommons.org/licenses/bync-nd/4.0/). Peer-review under responsibility of AMER (Association of Malaysian Environment-Behaviour Researchers), ABRA (Association of Behavioural Researchers on Asians) and CE-Bs (Centre for EnvironmentBehaviour Studies), Faculty of Architecture, Planning \& Surveying, Universiti Teknologi MARA, Malaysia.

https://doi.org/10.21834/aje-bs.v3i8.280 


\subsection{Introduction}

Various VM definitions confirmed VM as an approach that improve the worked relationship among the team and able to achieve better value for money for the projects (Kelly et. al 2004; Jaapar 2006; IVM 2008; SAVE 2008; Hayles 2010; and Perera et al. 2011 p.95). Hence, VM is a fundamental concept to be implemented in the public projects in order to accelerate further momentum of the country in achieving the developed nation status by 2020. Therefore, on December 2009, VM Circular 3/2009 had been authorised to embark the VM implementation in Malaysia. However, there is an issue on the receptiveness among the VM participants towards the VM workshops due to lack of knowledge, experience and exposure towards VM.

Sustainable VM applications in the future Malaysian construction industry are crucial. Hence, there is a need to study and monitor the VM participants' receptiveness and their behaviour towards the overall current VM application in the public projects.

The primary data gathered from the process provides an insight towards the socialcultural interrelationships between VM participants and the environment of VM workshops. Its outcome assisted the researchers on the VM evolution and how VM to be implemented in all projects, in a bigger scale. There are three (3) objectives to be achieved in this research.

The objectives are to identify the VM participants' receptiveness towards the VM implementation in the workshop environment setting, to observe the VM manual applications in the VM workshop and to discover the challenges faced by the VM participants and facilitators.

\subsection{Literature Review}

This section briefly discussed the implementation of VM in public projects in Malaysia, VM workshops, and function of capacity building in ensuring sustainable application of VM in the future.

\subsection{VM in Malaysian Public Projects}

Despite its infancy stage of implementation to the construction industry (Jaapar, 2006), on December 2009, the authorisation of Value Management Circular 3/2009 by Economic Planning Unit (EPU) has made all public projects exceeding RM50 million to implement the VM studies resulted in massive impact to the government projects' procurements process. In a month period, Ahmad (2011) stated that 71 projects had applied VM studies, which had resulted in $23.53 \%$ of monetary savings from the total overall cost.

By May 2011, in order to ensure standardisation in its implementation process, the EPU published the Manual of Value Management Implementation for Government Projects as a guideline for the key players of the construction industry to implement the VM studies.

The National Development Planning Committee (NDPC) were also formed to monitor and to ensure the implementation of VM in the government projects. Figure 1 shows the organisational structure for VM implementation in public projects. There are three (3) stages in VM application for public projects and each stage are handled by different government agencies. The process of VM application is being divided into three (3) which are the Value 
Assessment (VA), Value Engineering (VE) and Value Review (VR).

\subsection{Value Assessment (VA)}

Currently, the manual dictates VA process to be carried out as a strategic planning implemented before a project is approved. The term VA in the manual used to describe the process of planning the government project. The purpose of VA is to identify the projects that can contribute to the achievement of cost optimisation and improve the performance of the projects. At this stage, the VA is used as one of the management strategies to achieve value for money because the real needs of the projectcan be verified.

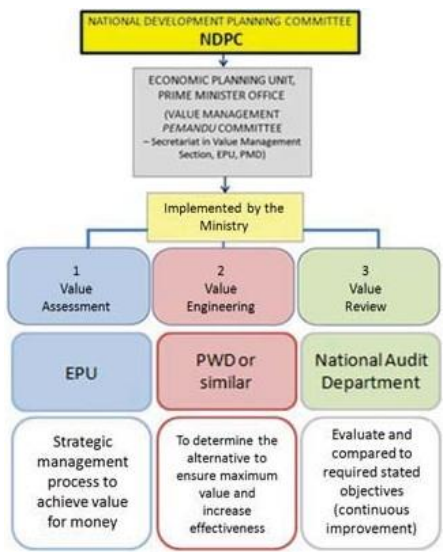

Figure 1: Organisational structure for VM implementation Adopted and modified from: VM Manual, EPU (2011) Value Engineering (VE)

For the project that has been approved at the central agencies level, implementing VE at all levels of design development to ensure the achievement of the functions and objectives as required. If necessary, VE can also be carried out repeatedly, especially for complex projects.

During this stage, the VE should be conducted to determine the alternatives and the best method to implement the projects in maximising value for money and improve the effectiveness of the project. This is usually done by excluding the function and specifications that unnecessary and suggest alternative which can improve the delivery of projects.

\subsection{Value Review (VR)}

VR in the manual refers to the process of VM implementation after the project is completed so that the project performance can be evaluated and compared to the required objectives. It is also an effort for continuous improvement to improve the weaknesses and improve effective implementation of the projects. At this stage, the effectiveness and weaknesses of a project will be informed to the relevant ministries and agencies to embedded or enhanced the future projects. 


\subsection{VM Workshop}

According to Jaapar et. al (2012), the current VM implementation process used is the "hybrid VM" workshop process which involves a team of facilitators who are able to handle more than one project simultaneously. The VM job plan is flexible depending on the project size and work stage.

Table 1 shows a comparison between original job plan by Miles (1972) and its evolution leading to job plan by Kelly et. al (2004), Jaapar (2006) and VM Manual by EPU (2011).

Table 1: Job Plan Comparison

\begin{tabular}{|c|c|c|c|}
\hline $\begin{array}{l}\text { VM Job Plan (Miles, } \\
\text { 1972) }\end{array}$ & $\begin{array}{l}\text { VM Methodology } \\
\text { (Kelly et al., 2004) }\end{array}$ & $\begin{array}{l}\text { Prototype Guideline } \\
\text { (Jaapar, 2006) }\end{array}$ & VM Manual (EPU, 2011) \\
\hline \multirow[t]{2}{*}{$\begin{array}{l}\text { Orientation } \\
\text { Information } \\
\text { Speculation } \\
\text { Analysis } \\
\text { Programme planning } \\
\text { Programme execution } \\
\text { Status summary } \\
\& \text { conclusion }\end{array}$} & \begin{tabular}{|l} 
Pre-study stage \\
Workshop stage \\
Information \\
Creativity \\
Evaluation \\
Development \\
Presentation
\end{tabular} & \begin{tabular}{|l|} 
Pre-workshop stage \\
Workshop stage \\
Information \\
Analysis \\
Creativity \\
Judgement \\
Development \\
Presentation
\end{tabular} & \begin{tabular}{|l} 
Pre workshop \\
Workshop \\
Information \\
Function Analysis \\
Creativity \\
Evaluation \\
Development \\
Presentation
\end{tabular} \\
\hline & Post-study stage & Post-workshop stage & Post workshop \\
\hline
\end{tabular}

Sources: Kelly et. al (2004), Jaapar (2006) and VM Manual, EPU (2011)

\subsection{Pre-Workshop}

The main purpose of the pre-workshop is to design the workshop, to gain the commitment of ministries' and agencies' top management in order to plan and decide the division of responsibilities and duties of officers and staff throughout the study. This stage focuses on preparing for the workshop stage including a site visit and collection of basic information of the project.

\subsection{Workshop}

\section{1) Information Phase (IP)}

The process of IP enables all participants to understand the process of the VM workshop and the nature of the project. The insight obtained during the phase is to ensure functions mismatch in the project to be discovered and hence it provide the basis to seek alternatives through the next process.

2) Function Analysis Phase (FAP)

The purpose of this phase is to understand the project through the function perspective. It emphasizes the question of what exactly is to be achieved by the project compared to the perception during project proposed.

3) Evaluation Phase (EP)

All the ideas generated are evaluated and being short-listed if it reduces investment cost, practical to implement, save time or contribute to the life cycle cost. 
4) Development Phase (DP)

The short-listed ideas developed into alternatives that increase the value of projects. This alternative translated in the form of drawings, diagrams and supported by calculations, information by the manufacturer / producer and other materials.

5) Presentation Phase (PP)

The PP phase is to inform the workshop recommendations and conclusions to the top management, other stakeholders and the policy makers. PP allows the management or policy-making decisions, which compatible with the achievement of an objective or policy of the Government.

\subsection{Post Workshop}

After the presentation phase, management and project implementing agencies should consider implementing the proposed alternative. At this stage, the question of how and when the project will be made should be set. In certain circumstances, further studies may be required if the policy makers or senior management have a reason. It is the responsibility of ministries and implementing agencies to ensure the implementation of the workshop results.

\subsection{Capacity Building}

Virji et. al (2012) also referred capacity building as capacity development or capacity strengthening which is related to sustainable development. However, there are many different ways in which various international developments platforms approach and facilitate capacity building in their work. Capacity building in this context follows the definition given by Mugabe etal. (2000) as the knowledge-intensive process of creating, mobilizing, utilizing, improving, transferring, and sustaining individual, institutional and country expertise/ skills for addressing a specific problem or a multitude of challenges.

In ensuring the implementation of VM to the Malaysian construction industry, it is suggested the theory of capacity building is to be use to ensure all the related human, organisation and institutional resources are channel towards ensuring sustainable VM implementation in future.

\subsection{Methodology}

For this research, five (5) public projects that implemented VM study were observed and recorded by the researchers through participative observations process. The outcome of this preliminary research provides an insight towards the area further. Hence, it will provide a better platform for a detailed study on VM studies.

The observations periods were from February 2011 to June 2012. The observed projects total value were more than RM600 million. Confidentiality issues such as nature and stage of the projects were among the reasons why permissions for observation were not granted for some other projects.

The outcome in a form of projects' document, VM study process and VM participants' participation were analysed either on the printed documents or electronic documents such as projects' drawing, details and presentation materials. 
The first instrument of the research method was by face-to-face interviews, assisted by recording tools such as sound and visual recording mechanisms to the individuals that involved in the VM workshops that had been observed by the researchers. Eight (8) respondents interviewed were the facilitators, clients and consultants. The interviewees were selected due to their continuously participation in all the observed VM implemented projects.

\subsection{Findings and Discussion}

From the observations process, the repeated VM participants' receptiveness towards workshops was positive, and they indicated their sincere intention to deal fairly witheachother. They were enthusiastic and cooperative during the VM workshops. This could be because of awareness among the parties involved on urgent and needs of the VM to the projects. They were positive during the VM awareness stage and got along well with each otherduring the VM workshop.

However, it was different to the participants that experienced the VM workshop for the first time. It is supported by the previous research that most of the VM participants, especially the consultants had a negative perception towards VM, but they changed their perception towards the end of the workshop and accepted the VM concept. Even though initially their receptiveness towards VM workshop was low and sceptical, but they did give cooperation throughout the workshop.

From the observation of five (5) VM case studies, it was discovered that the VM workshops were implemented according to the VM manual by the EPU. Based on the data analysis, all VM workshops were conducted according toEPU's guideline. Itwas supported by other respondents that the VM workshop was conducted according to the VM job plan and paralleled to the agenda that had been distributed earlier.

According to the observations process, the VM workshops for public projects start with a briefing on the VM process by the VM facilitator before starting the actual workshop. It would be followed with the presentation session for projects scope by the client and consultants and brainstorming session. VM workshop usually was conducted through participation from all the members in the group session by triggers all the ideas to be evaluated. It was similar to the brainstorming session which required the members to come out with the ideas, alternatives and strategies to be implemented in the project.

It was observed that the VM workshop was led by the VM facilitator throughout the VM process. The VM participants were also assisted by the VMfacilitator ateach phase. However, the time control is always a problem during each phase. The VM facilitator to give attention on time in order to ensure the punctuality of the VM workshop.

Based on data analysis, it was discovered several challenges that faced by the VM participants during the VM workshop. One of the challenges was the VM workshop could not be smoothly implemented due to insufficient information provided. This may result to inaccurate judgement especially related to costing. Besides, it was difficult to achieve the outcome that could satisfy every party involved in the workshop.

VM facilitator has a prominent role in VM workshop, therefore, having knowledge on VM methodology, experience and skills are critical. Constantly, VM facilitator was to handle 
different types of people with different character, values and background. Moreover, VM facilitator should know how to attract the VM participants to be active during the workshop.

Consistent with the previous observation, the information providers, were found difficult to cope with the discussion during the VM workshop. They tend to stay at the back while watching the VM team discussed on the project. Occasionally, the information providers will interrupt during the presentation session at the end of each phase.

\subsection{Conclusion}

As a conclusion, it is discovered that the VM participants' receptiveness towards VM application is positive and highly cooperative throughout the VM workshops process Even though the first time participants were sceptical towards the VM concept at first; it changed towards the end of the VM workshops and accepted the needs of VM implementation to the projects' benefits.

Throughout the observations, it is discovered that the VM implementation in the public projects was according to the VM manual by EPU. Even though the duration of the VM workshops was not consistent with the VM manual, but the VM studies still held according to the VM phase as in manual. It was due to the nature of the project itself (Jaapar, 2012).

This research also discovered the challenges that faced by the VM participants during the VM studies. The challenges faced by them are insufficient information provided, difficult to achieve the outcome that could satisfy every party involved in the workshop, and difficult to handle different types of people with different character, values and background.

Even though, this research had discovered the VM participants' receptiveness towards VM application in public projects; however, it was only focused on five VM case studies and still at a preliminary stage of implementation. For further research in the future, it is recommended to undertake a study on the acceptance of the VM participants at each stage of VM with wider sample of respondents and case studies.

\section{Acknowledgements}

Utmost appreciations to the respondents who agreed to be interviewed and gave us the benefits for the knowledge, views and experience. Special thanks are dedicated to Value Management Section, Economic Planning Unit, Prime Minister Office and all parties involved for their significant cooperation and provided us with the valuable information on the case studies related for this research.

\section{References}

Ahmad, N. (2011). Keynote Speaker for Value Management Seminar, Economic Planning Unit of Prime Minister Department, Putrajaya International Convention Center. 24 May 2011.

Economic Planning Unit Malaysia (2009). Garis Panduan Pelaksanaan Pengurusan Nilai (Value Management). 
Economic Planning Unit Malaysia (2011). Panduan Pelaksanaan Pengurusan Nilai (Value Management) dalam Program/Projek Kerajaan.

Hayles, C. S., Graham, M. \& Fong, P. W. S. (2010). "Value Management as a framework for embedding sustainable decisionmaking", Proceedings of ICE - Municipal Engineer, Vol. 163 No. 1, 43-50.

Jaapar, A. (2006). The application of value management in the Malaysian construction industryand developmentor prototype value management guidelines. Unpublished PhD Thesis. UiTM Shah Alam.

Jaapar, A. et al. (2012). Value Management in the Malaysian Construction Industry: Addressing a Theory and Practice Gap. Procedia-Social and Behavioral Sciences, 757-763.

Kelly, et al. (2004). Value Management of Construction Projects. Oxford: Blackwell Science Ltd..

Miles L. D. (1972). Technique of Value Analysis and Engineering, $2^{\text {nd }}$ ed.

New York: The Mac Graw Hill.

Mugabe, J. et. al (2000). Capacity development initiative. Country Capacity Development Needs and Priorities Regional Report for Africa. GEF UNDP Strategic Partnership.

Perera. S., Hayles, C. S. \& Kerlin, S. (2011). An analysis of value management in practice: The case of Northern Ireland's construction industry. Journal of Financial ManagementofPropertyand Construction, Vol. 16 No. 2, 94-110.

Society of American Value Engineers (2008). What is value engineering? Avaiworkshople: http://www.valueeng.org/(Accessed:February25 $\left.5^{\text {th }}, 2012\right)$.

The Institute of Value Management (2008). What is Value Management? Avaiworkshople: http://www.ivm.org.uk/what_vm.htm (Accessed: February 25th, 2012).

Virji, H., Padgham, J., \& Seipt, C. (2012). Capacity building to support knowledgesystemsforresilientdevelopment -approaches, actions, and needs. Current Opinion in Environmental Sustainability, 4:115-121. 